\title{
Identifikasi Citra Digital Jenis Beras Menggunakan Metode Anfis dan Sobel
}

\author{
Gansar Suwanto', Riza Ibnu Adam², Garno ${ }^{3}$ \\ 1,2,3 Teknik Informatika, Fakultas Ilmu Komputer, Universitas Singaperbangsa Karawang \\ ${ }^{1}$ gansar.16094@student.unsika.ac.id, ${ }^{2}$ riza.adam@staff.unsika.ac.id, ${ }^{3}$ garno@staff.unsika.ac.id
}

\begin{abstract}
Abstrak
Beras merupakan salah satu produk unggulan pangan nasional dan produk unggulan pertanian di Indonesia. Banyaknya jenis-jenis beras di Indonesia menyebabkan semakin sulitnya membedakan beras hanya mengandalkan mata saja. Dikarenakan setiap jenis beras memiliki ciri bentuk dan tekstur yang relatif berbeda. Oleh karena itu, citra digital dapat dijadikan langkah awal dalam mengidentifikasi jenis-jenis beras. Penelitian ini bertujuan untuk mengidentifikasi jenis-jenis beras dengan menggunakan pengolahan citra. Pengambilan nilai ciri bentuk menggunakan metode morfologi dan dibandingkan dengan metode sobel. Sedangkan pengambilan nilai ciri tekstur menggunakan metode citra grayscale. Kemudian, nilai bentuk dan tekstur lakukan pengelompokan sesuai jenis beras. Data yang digunakan dalam penelitian ini adalah 140 citra. 100 dari 140 citra tersebut dilakukan pelatihan dengan menggunakan metode ANFIS (Adaptive Neuro Fuzzy Inference System) dengan memanfaatkan nilai bentuk dan tekstur citra. Pengujiaan dilakukan sebanyak 5 kali dengan menggunakan 140 citra tersebut. Hasil pengujian dengan metode ANFIS (Adaptive Neuro Fuzzy Inference System) sebesar 85.2\%. Sedangkan, Deteksi tepi sobel dapat mempengaruhi akurasi sebesar $3 \%$.
\end{abstract}

Kata kunci : ANFIS, beras, kecerdasan buatan, sobel, pengolahan citra digital.

\section{Pendahuluan}

Indonesia mempunyai beragam macam jenis beras, contohnya adalah Pandan wangi Cianjur, Rojo Lele, IR 42, IR 46, poles, dan muncul. Salah satu permasalahan dari beras ialah membedakan berbagai jenis beras dikarenakan semakin banyaknya jenisjenis beras maka semakin sulit membedakan jenis beras dengan hanya mengandalkan mata saja. Dapat dilihat dari berbagai bentuk beras yang memiliki berbagai bentuk dari mulai pendek tipis, pendek besar, panjang tipis, dan panjang besar. Belum lagi jika dilihat dari warna beras ada yang putih susu, bening ke kuning kuningan, dan bening.

Perkembangan ilmu pengetahuan dan teknologi sekarang ini dapat menghasilkan berbagai perkembangan komputerisasi untuk dapat dimanfaatkan dalam membantu manusia memperoleh informasi data yang lebih akurat dan dapat dipertanggung jawabkan. Bahkan para ahli sudah bisa menciptakan komputer yang dapat meniru kemampuan berpikir manusia. Sehingga lahir teknologi kecerdasan buatan (Artificial Intellegence). Oleh karena itu proses klasifikasi jenis beras dapat menggunakan bantuan komputasi dengan metode image processing serta algoritma AI (artificial Intelegent). Pada penelitian sebelumnya peran metode image processing beserta AI telah berhasil menerapkan sistem keamanan parkir dengan memanfaatkan no plat kendaraan (Wahyu \& Suhendri, 2019).

Terdapat banyak algoritma AI (Artificial Intelegent) seperti Jaringan saraf Tiruan, Fuzzy Logic, dan ANFIS (Adaptive Neuro Fuzzy Inference System). Dari ketiga algoritma yang telah disebutkan ANFIS terbukti sangat baik digunakan dalam prediksi dengan teknik pelatihan yang sangat sederhana (Rayendra, 2018). Pada dasarnya Adaptive Neuro Fuzzy Inference System (ANFIS) merupakan suatu jaringan kerja antara jaringan syaraf tiruan dengan sistem inferensi fuzzy model sugeno (Umam et al., 2016). Pada penelitian sebelumnya ANFIS dapat digunakan untuk membangun prediksi tingkat layanan berdasarkan level of service (Azizah, 2016), bisa dipergunakan juga untuk mengidentifikasi biometric irisan mata (Umam et al., 2016) dan ada pula yang menggunakan anfis untuk diagnosis penyakit jantung (Holle et al., 2016).

Pengolahan citra dapat meningkatkan nilai akurasi yang tinggi dalam mengidentifikasi jenis beras dengan manipulasi citra menjadi citra yang memiliki kualitas lebih baik agar mudah diinterpretasikan oleh manusia atau mesin (computer). Salah satu metode pengolahan citra yang biasa digunakan adalah segmentasi citra.

Deteksi tepi merupakan proses untuk menentukan lokasi titik-titik yang merupakan tepi obyek 
(Romindo \& Khairina, 2017). Terdapat beberapa teknik yang digunakan untuk mendeteksi tepi antara lain metode sobel, metode prewitt, metode robert, metode canny, metode Laplacian Gaussia, metode gaussian (Letelay, 2019). Menurut (Dianta, 2012) metode sobel adalah metode yang paling banyak digunakan sebagai pendeteksi tepi karena kesederhanaan dan keampuhannya.

Pada penelitian sebelumnya (Ricardo \& Gasim, 2019) mengatakan akurasi pengenalan jenis beras menggunakan algoritma propagasi balik dengan ratarata akurasi sebesar $82 \%$. Penelitian ini bermaksud untuk mengetahui hasil dari perbandingan antara akurasi pengenalan jenis beras menggunakan algoritma propagasi balik dengan metode ANFIS. Hasil dari penelitian ini dapat dijadikan bahan pertimbangan dalam memilih algoritma yang terbaik untuk pengenalan jenis beras.

\section{Landasan Teori}

\subsection{Beras}

Padi erat hubungannya dengan manusia karena setengah dari penduduk dunia mengkonsumsi nasi dari olahan tanaman padi. Hal itu karena padi mengandung karbohidrat yang meningkatkan energi dalam tubuh. Selain mengandung energi yang tinggi padi juga memiliki kandungan serat rendah yang dapat mengobati dan mencegah gangguan pencernaan (Ramadhona et al., 2018).

\subsection{Pengolahan Citra}

Pengolahan Citra bertujuan memperbaiki kualitas citra agar mudah diinterpretasi oleh manusia atau mesin (dalam hal ini komputer). Teknik-teknik pengolahan citra mentransformasikan citra menjadi citra lain. Jadi, masukannya adalah citra dan keluarannya juga citra, namun citra keluaran mempunyai kualitas lebih baik daripada citra masukan. Termasuk ke dalam bidang ini juga adalah pemampatan citra (image compression)(Anas, 2017).
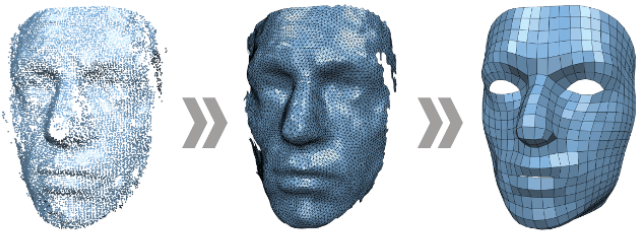

Gambar 1. Image Processing

\subsection{Akuisisi Citra}

Akuisisi data adalah tahap dalam mendapatkan citra. Tujuan dari tahap ini adalah untuk menentukan data yang dibutuhkan dan memilih metode perekaman citra digital. Langkah-langkah yang dilakukan dalam ini secara umum dimulai dari persiapan obyek yang akan diambil citranya, alat-alat, sampai pada pencitraan (Kusumadewa \& Supatman, 2018).

\subsection{Segmentasi Citra}

Pertama dilakukan segmentasi citra biner. Tujuan segmentasi adalah mendapatkan representasi sederhana dari suatu citra sehingga lebih mudah dalam pengolahannya (Nurcahyani \& Saptono, 2015).

\subsection{Model Warna}

RGB adalah warna dasar yang dijadikan patokan warna secara universal (primary colors) dengan citra jenis berwarna yang bisa diubah warnanya ke dalam kode-kode angka sehingga warna tersebut akan tampil universal (Pratama et al., 2019).

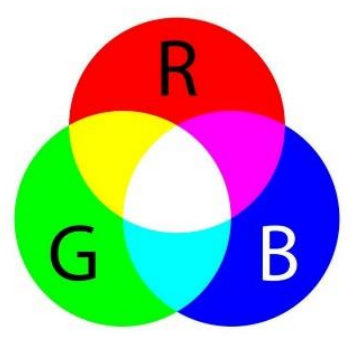

Gambar 2. Citra RGB

\subsection{Ekstrasi Ciri Bentuk dan Tekstur}

Pengenalan pola bentuk merupakan metode yang meggunakan dua kombinasi parameter yaitu eccentricity dan metric dari suatu objek pada citra biner. Parameter eccentricity dan metric merupakan teknik ekstraksi fitur yang bertujuan untuk mengambil atau mengekstraksi nilai eccentricity dan metric (Widians et al., 2019).

Pengertian dari tekstur dalam hal ini kurang lebih adalah keteraturan pola-pola tertentu yang terbentuk dari susunan piksel-piksel dalam citra digital (Widians et al., 2019).

\subsection{Deteksi Tepi}

Deteksi tepi yaitu proses untuk menentukan lokasi titik-titik yang merupakan tepi objek. Deteksi tepi menggunakan operasi yang dijalankan untuk mendeteksi garis tepi (edges) yang membatasi dua wilayah citra homogen yang memiliki tingkat kecerahan yang berbeda (Romindo \& Khairina, 2017).

\subsection{Adaptive Neuro Fuzzy Inference System}

Adaptive Neuro Fuzzy Inference Sistem (ANFIS) adalah suatu jaringan kerja antara jaringan syaraf tiruan dengan sistem inferensi Fuzzy (Fuzzy 
Inference Sistem) model Sugeno. Sistem ini disebut juga suatu kelas jaringan adaptif yang secara fungsional sama dengan sistem inferensi Fuzzy (FIS), atau disebut juga dengan Adaptive Network-based Fuzzy Inference Sistem (Umam et al., 2016).

\subsection{MATLAB}

Pada bidang komputasi, Matlab dapat digunakan untuk akuisisi citra digital, termasuk juga dalam hal pengembangan dan algoritma. Permodelan, simulasi sampai pembuatan prototype juga berkaitan erat dengan komputasi (Atina, 2019).

\section{Metodologi Penelitian}

\subsection{Objek Penelitian}

Objek dalam penelitian ini adalah Citra digital dari jenis beras (Ciherang IR 64, Rojolele, dan Pandan Wangi). Jumlah citra beras adalah140 citra. Citra tersebut disamaratakan ukurannya menjadi sebesar 300 x 300 dengan format .png.

\subsection{Metode}

Penelitian ini menggunakan metode eksperimental. Metode eksperimental merupakan metode yang digunakan untuk mengetahui sebabakibat dari suatu kejadian. Tahapan yang terdapat dalam metode ekperimental adalah sebagai berikut: Pemilihan ide atau topik penelitian, Merumuskan masalah penelitian, merumuskan hipotesa, Menentukan variabel, Menentukan tipe dan desain penelitian, Merancang dan melaksanakan penelitian, Menganalisis hasil penelitian, dan membuat kesimpulan. Adapun dalam pelaksanaan penelitian ini mengacu pada rancangan penelitian yang dapat diliat pada Gambar 1.

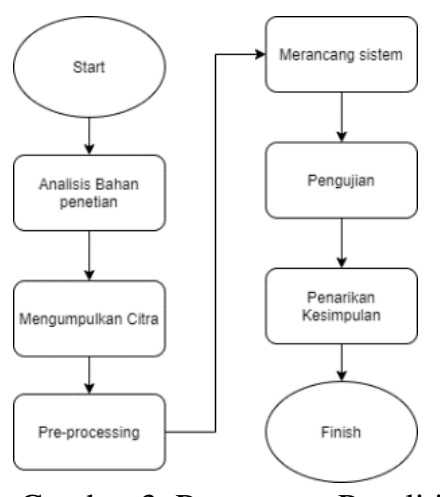

Gambar 3. Rancangan Penelitian

\section{Hasil Penelitian}

\subsection{Bahan Penelitian}

Pada tahap awal ini, penulis membutuhkan empat jenis beras untuk dijadikan citra digital, beras tersebut ialah Beras Ciherang, Beras IR 64, Beras
Rojolele, dan Beras Pandan Wangi. Dalam pengambilan citra digital jenis beras, penulis membutuhkan alat bantu guna menyamarakan citra digital jenis beras. Alat tersebut dibuat menggunakan papan triplek yang akan dibentuk menjadi persegi dengan panjang $35 \mathrm{~cm}$, lebar $35 \mathrm{~cm}$, dan tinggi $25 \mathrm{~cm}$. Di dalam kotak tersebut diberikan penerangan menggunakan 2 buah lampu LED (Light Emitting Diode) 6 watt. Untuk mempermudah proses memisahkan objek dengan latar digunakan lah background berwarna hitam.

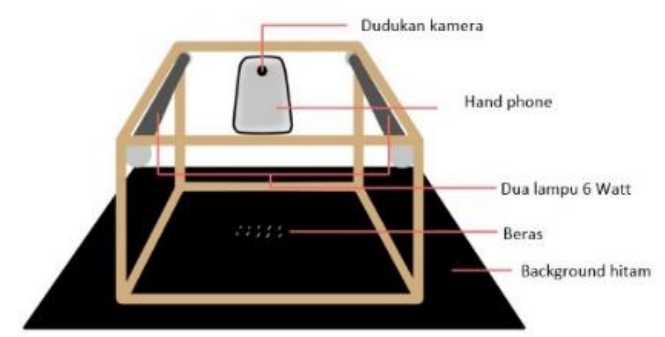

Gambar 4. Sketsa Alat Bantu Pengambilan Citra

\subsection{Mengumpulkan Citra}

Beras yang akan dilakukan pengambilan citranya dengan cara menyusunnya pada background hitam dengan penempatan posisi 5 baris dan 5 kolom. Beras yang kualitasnya bagus atau bisa dikatakan butir beras tidak pecah yang penulis jadikan sebagai objek dalam pengambilan citra. Proses pengambilan citra beras dilakukan berulang-ulang dengan menggunakan kamera 12 megapixel, untuk dijadikan citra latih dan citra uji. Setiap satu kali pengambilan citra beras dilakukan penggantian butir beras guna dapat mendapatkan data yang lebih banyak untuk dilakukan pembelajaran sehingga akurasi yang didapatkan dapat meningkat.

\subsection{Preprocessing}

Proses preprocessing dilakukan untuk memperoleh citra yang selanjutnya dapat dimanfaatkan untuk sistem yang akan dibuat. Proses ini meliputi proses cropping, compressing size citra, segmentasi citra dan menutup noise pada citra. proces cropping, compressing size citra dilakukan secara manual dengan menggunakan software pendukung photoscape. Cropping citra dilakukan dengan perbandingan 1:1 dengan size citra sebesar 300 X 300 pixel. proses ini dilakukan menggunakan aplikasi pendukung seperti photoscape Setelah melalui proses cropping dan resize citra untuk menyamaratakan citra dapat dilanjutkan ke proses segmentasi. Proses 
segmentasi pada penelitian kali ini menggunakan metode otsu thresholding, morfologi dan deteksi tepi yang dilakukan pada software MATLAB.

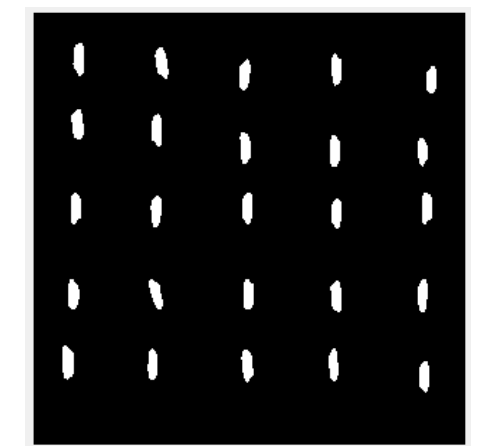

Gambar 5. Citra Hasil Morfologi

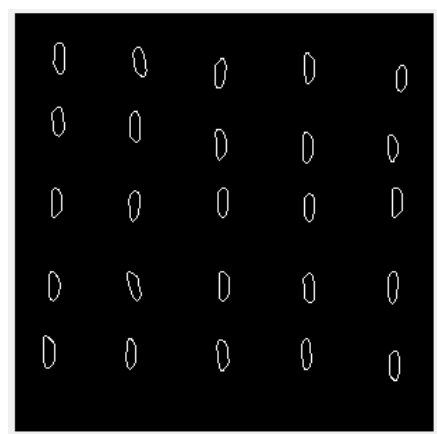

Gambar 6. Citra Hasil Deteksi Tepi Sobel

\subsection{Perancangan Sistem}

Pada tahap ini sistem akan dibuat menggunakan software MATLAB. Sistem ini digunakan untuk proses pelatihan dan pengujian dengan menggunakan metode ANFIS (Adaptive Neuro Fuzzy Inference System). Adapun tahap yang harus dilakukan ialah Load Data, Membuat Arsitektur ANFIS dan Melakukan Pelatihan

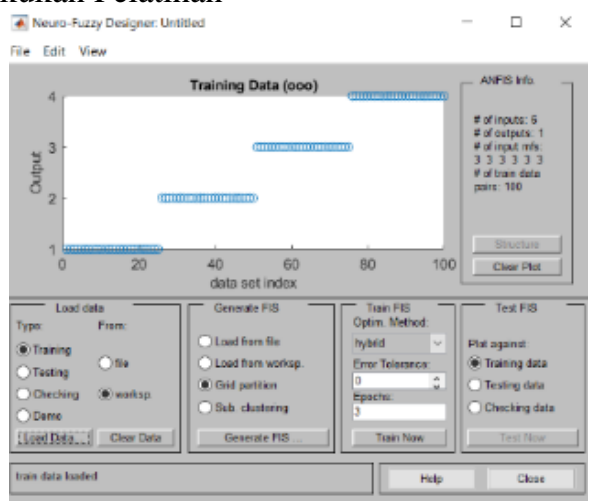

Gambar 5. Load Data

Selanjutnya menentukan parameter-parameter fungsi keanggotaan dalam ANFIS. untuk melakukannya, terdapat pada kolom generate ANFIS dengan memilih GridPartition. Kemudian tentukan banyaknya inputan MF (membership function) sebanyak 2 dengan type trapesium untuk masingmasing inputan 1 hingga 6. Sedangkan untuk type $\mathrm{MF}$ (membership function) pilih linear.

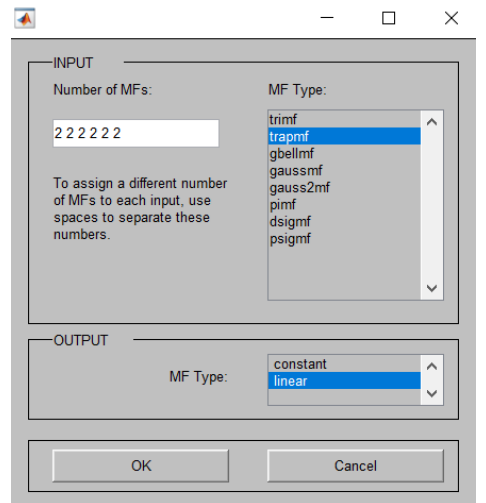

Gambar 7. Pembuatan Arsitektur Pelatihan ANFIS

Terdapat 2 metode pelatihan di dalam ANFIS yang pertama ialah metode back propagation dan yang kedua metode hybrid. Pada penelitian kali ini penulis menggunakan pelatihan hybrid dengan total pembelajaran sebanyak 20 kali. Didapatkan lah minimal training RMSE sebesar 0.042594. dengan jumlah rule yang didapatkan sebanyak 64 dan output MF (membership function) sebanyak 64. Dari pelatihan tersebut didapatkanlah struktur pelatihan yang dapat dilihat pada Gambar 7 .

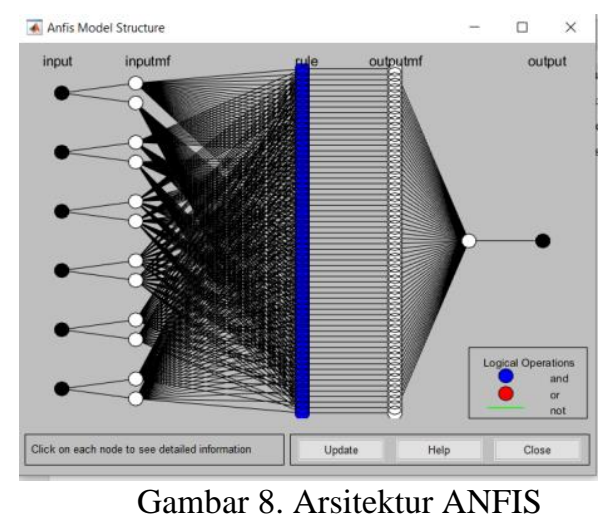

\subsection{Pengujian}

Pengujian dalam penelitian kali ini ialah meliputi mencari nilai akurasi yang didapat dalam mengidentifikasi jenis beras. pengujian dilakukan sebanyak 5 kali. Pertama ialah pengujian dengan citra latih $100 \%$, kemudian pengujian dengan citra latih sebanyak $90 \%$ dan citra uji sebanyak $10 \%$, yang ketiga pengujian dengan citra latih sebanyak $80 \%$ dan citra uji sebanyak $20 \%$, keempat pengujian dengan citra latih sebanyak $70 \%$ dan citra uji sebanyak $30 \%$, dan yang terakhir pengujian degan citra latih sebanyak $60 \%$ dan citra uji sebanyak $40 \%$.

Tabel 1. Hasil Identifikasi Citra Latih 100\%

\begin{tabular}{ccccc}
\hline \multirow{2}{*}{$\begin{array}{c}\text { Nama } \\
\text { Folder }\end{array}$} & Jenis & Jumlah & \multicolumn{2}{c}{ Hasil Identifikasi } \\
\cline { 4 - 5 } & Citra & Citra & $\begin{array}{c}\text { Dengan } \\
\text { Sobel }\end{array}$ & $\begin{array}{c}\text { Tanpa } \\
\text { Sobel }\end{array}$ \\
\hline Citra & Ciherang & 25 & 25 & 25 \\
Latih & IR 64 & 25 & 25 & 25
\end{tabular}




\begin{tabular}{cccc} 
Rojolele & 25 & 25 & 25 \\
Pandan & 25 & 25 & 25 \\
Wangi & & & \\
Akurasi & & $\mathbf{1 0 0 \%}$ & $\mathbf{1 0 0 \%}$ \\
\hline
\end{tabular}

Tabel 2. Hasil Identifikasi Citra Latih 90\% dan Citra Uji $10 \%$

\begin{tabular}{ccccc}
\hline \multirow{2}{*}{$\begin{array}{c}\text { Nama } \\
\text { Folder }\end{array}$} & Jenis & Jumlah & \multicolumn{2}{c}{ Hasil Identifikasi } \\
\cline { 4 - 5 } & & Citra & $\begin{array}{c}\text { Dengan } \\
\text { Sobel }\end{array}$ & $\begin{array}{c}\text { Tanpa } \\
\text { Sobel }\end{array}$ \\
\hline Citra & Ciherang & 25 & 21 & 22 \\
Uji 3 & IR 64 & 25 & 22 & 22 \\
& Rojolele & 25 & 24 & 25 \\
& Pandan & 25 & 23 & 23 \\
& Wangi & & & \\
& Akurasi & & $\mathbf{9 0 \%}$ & $\mathbf{9 2 \%}$ \\
\hline
\end{tabular}

Tabel 3. Hasil Identifikasi Citra Latih $80 \%$ dan Citra Uji $20 \%$

\begin{tabular}{ccccc}
\hline \multirow{2}{*}{$\begin{array}{c}\text { Nama } \\
\text { Folder }\end{array}$} & Jenis & Citra & Jumlah & \multicolumn{2}{c}{ Hasil Identifikasi } \\
\cline { 4 - 5 } & & & $\begin{array}{c}\text { Dengan } \\
\text { Sobel }\end{array}$ & $\begin{array}{c}\text { Tanpa } \\
\text { Sobel }\end{array}$ \\
\hline Citra & Ciherang & 25 & 18 & 19 \\
Uji 1 & IR 64 & 25 & 21 & 20 \\
& Rojolele & 25 & 24 & 25 \\
& $\begin{array}{c}\text { Pandan } \\
\text { Wangi }\end{array}$ & 25 & 21 & 21 \\
& Akurasi & & $\mathbf{8 4 \%}$ & $\mathbf{8 5 \%}$ \\
\hline
\end{tabular}

Tabel 4. Hasil Identifikasi Citra Latih 70\% dan Citra Uji $30 \%$

\begin{tabular}{ccccc}
\hline \multirow{2}{*}{$\begin{array}{c}\text { Nama } \\
\text { Folder }\end{array}$} & Jenis & Jumlah & \multicolumn{2}{c}{ Hasil Identifikasi } \\
\cline { 4 - 5 } & Citra & $\begin{array}{c}\text { Dengan } \\
\text { Sobel }\end{array}$ & $\begin{array}{c}\text { Tanpa } \\
\text { Sobel }\end{array}$ \\
\hline Citra & Ciherang & 25 & 18 & 19 \\
Uji 4 & IR 64 & 25 & 21 & 18 \\
& Rojolele & 25 & 22 & 22 \\
& Pandan & 25 & 19 & 18 \\
& Wangi & & & \\
& Akurasi & & $\mathbf{8 0 \%}$ & $\mathbf{7 7 \%}$ \\
\hline
\end{tabular}

Tabel 5. Hasil Identifikasi Citra Latih 60\% dan Citra Uji $40 \%$

\begin{tabular}{|c|c|c|c|c|}
\hline \multirow{2}{*}{$\begin{array}{l}\text { Nama } \\
\text { Folder }\end{array}$} & \multirow{2}{*}{$\begin{array}{l}\text { Jenis } \\
\text { Citra }\end{array}$} & \multirow{2}{*}{$\begin{array}{c}\text { Jumlah } \\
\text { Citra }\end{array}$} & \multicolumn{2}{|c|}{ Hasil Identifikasi } \\
\hline & & & $\begin{array}{c}\text { Dengan } \\
\text { Sobel }\end{array}$ & $\begin{array}{c}\text { Tanpa } \\
\text { Sobel } \\
\end{array}$ \\
\hline \multirow{4}{*}{$\begin{array}{l}\text { Citra } \\
\text { Uji } 2\end{array}$} & Ciherang & 25 & 18 & 19 \\
\hline & IR 64 & 25 & 18 & 18 \\
\hline & Rojolele & 25 & 21 & 21 \\
\hline & $\begin{array}{l}\text { Pandan } \\
\text { Wangi }\end{array}$ & 25 & 16 & 14 \\
\hline
\end{tabular}

\begin{tabular}{lll} 
Akurasi & $\mathbf{7 3 \%}$ & $\mathbf{7 2 \%}$ \\
\hline
\end{tabular}

\subsection{Penarikan Kesimpulan}

Berdasarkan Tabel 4.2 s/d 4.6 dapat diketahui bahwa rata-rata akurasi yang di dapat adalah $85.2 \%$. Sedangkan Deteksi tepi Sobel tidak banyak mempengaruhi akurasi dalam mengidentifikasi jenis beras hanya sekitar $3 \%$.

\section{Kesimpulan dan Saran}

\subsection{Kesimpulan}

Berdasarkan hasil penelitian yang telah dilaksanakan maka didapatkan kesimpulan bahwa;

Identifikasi citra digital jenis beras menggunakan metode ANFIS (Adaptive Neuro Fuzzy Inference System) melalui kombinasi penggunaan GLCM, LBP (local Binary Pattern), eccentricity dan metric dalam pengambilan nilai akstrasi ciri citra. Pengujian menggunakan $100 \%$ Citra latih, $90 \%$ citra latih $10 \%$ citra uji, $80 \%$ citra latih $20 \%$ citra uji, $70 \%$ citra latih $30 \%$ citra uji, $60 \%$ citra latih $40 \%$ citra uji. Dari hasil pengujian tersebut dapatkan rata-rata akurasi dalam mengidentifikasi citra digital jenis beras sebesar $85.2 \%$. Nilai tersebut dapat dikatakan cukup baik dikarenakan akurasi telah melebihi $70 \%$.

Deteksi tepi sobel dapat diterapkan sebagai metode tambahan dalam mengidentifikasi jenis beras menggunakan metode ANFIS. namun dalam segi akurasi, deteksi tepi sobel tidak banyak mempengaruhi akurasi, hanya sekitar 3\%. Hal tersebut disebabkan deteksi tepi sobel hanya dapat digunakan untuk mengambil bentuk objek saja.

\subsection{Saran}

Dari hasil penelitian yang dilakukan, maka saran-saran yang diberikan untuk referensi penelitian selanjutnya yaitu;

Diharapkan pada penelitian selanjutnya bisa menambahkan jumlah inputan agar mendapatkan akurasi yang lebih tinggi.

Pada penelitian kali ini ingin mengetahui pengaruh deteksi tepi sobel dalam akurasi identifikasi jenis beras, diharapkan dapat membandingkan dengan deteksi tepi lainnya seperti canny, prewitt, Robert dan $\log$.

Penelitian kali ini menggunakan inputan MF (membership function) pada pelatihan ANFIS sebanyak 2 inputan MF (membership function). Diharapkan dapat melakukan pelatihan ANFIS dengan lebih banyak inputan MF (membership function).

\section{Daftar Pustaka:}

Anas, A. (2017). Penentuan Threshold Citra Mulut Dengan Metode Normal Probability Density Function (Npdf) Guna Mendeteksi Mulut Pemelajar. ILKOM Jurnal Ilmiah, 9(2), 137- 
144.

https://doi.org/10.33096/ilkom.v9i2.135.137144

Atina. (2019). Aplikasi Matlab pada Teknologi Pencitraan Medis. Jurnal Penelitian Fisika Dan Terapannya (JUPITER), 1(1), 28. https://doi.org/10.31851/jupiter.v1i1.3123

Azizah, N. (2016). Metode Adaptive Neuro Fuzzy Inference System (ANFIS) untuk Prediksi Tingkat Layanan Jalan. Jurnal Sistem Informasi Bisnis, 7(1), 98-103. https://doi.org/10.21456/vol3iss3pp

Dianta, E. G. (2012). Deteksi Tepi Menggunakan Metode Canny Dengan Matlab Untuk Membedakan Uang Asli dan Uang Palsu. Jurnal Jurusan Teknik Informatika, Fakultas Teknologi, Industri Universitas Gunadarma, 1(1), 1-13.

Holle, K. F. H., Ludviani, R., \& Cahyani, L. (2016). Diagnosis Penyakit Jantung Menggunakan Adaptive Neuro-Fuzzy Inference System (ANFIS). Jurnal Ilmu Komputer Dan Teknologi Informasi, 8(2), 44-47. https://doi.org/10.18860/mat.v8i2.3537

Kusumadewa, C. C., \& Supatman. (2018). Identifikasi Citra Daun Teh Menggunakan Metode Histogram untuk Deteksi Dini Serangan Awal Hama Empoasca. Jurnal Multimedia \& Artificial Intelligence, 2(1), 2736.

Letelay, K. (2019). Perbandingan Kinerja Metode Deteksi Tepi. J-Icon, 7(1), 1-8.

Nurcahyani, A. A., \& Saptono, R. (2015). Identifikasi Kualitas Beras dengan Citra Digital. Scientific Journal of Informatics, 2(1), 63-72. https://doi.org/10.15294/sji.v2i1.4530

Pratama, R., Fuad, A., \& Tempola, F. (2019). Deteksi Kematangan Buah Tomat Berdasarkan Fitur Warna Menggunakan Metode Transformasi Ruang Warna HIS. JIKO (Jurnal Informatika Dan Komputer), 2(2), 81-86. https://doi.org/10.33387/jiko.v2i2.1318

Ramadhona, G., Setiawan, B. D., \& Bachtiar, F. A. (2018). Prediksi Produktivitas Padi Menggunakan Jaringan Syaraf Tiruan Backpropagation. Jurnal Pengembangan Teknologi Informasi Dan Ilmu Komputer, 2(12), 6048-6057.

Rayendra. (2018). Penerapan Metode ANFIS untuk Prediksi Nilai Akhir dan Kelulusan Uji Kompetensi. Jurnal Sains Dan Informatika, 4(1), 21-28. https://doi.org/10.22216/jsi.v4i1.2756

Ricardo, D., \& Gasim, G. (2019). Perbandingan Akurasi Pengenalan Jenis Beras dengan Algoritma Propagasi Balik pada Beberapa Resolusi Kamera. Jurnal RESTI (Rekayasa Sistem Dan Teknologi Informasi), 3(2), 131140. https://doi.org/10.29207/resti.v3i2.894

Romindo, \& Khairina, N. (2017). Analisa
Perbandingan Metode Edge Detection Roberts dan Prewitt. In Seminar Nasional Teknologi Informatika.

Umam, B. A., Sunaryo, \& Yudaningtyas, E. (2016). Implementasi Metode Anfis-Minkowski Untuk Identifikasi Biometrik Iris Mata Menggunakan Image Processing. Jurnal Ilmiah NERO, 2(1), 29-36.

Wahyu, A. P., \& Suhendri. (2019). Peningkatan Sistem Keamanan Parkir dengan Teknologi Artificial Intelligence Imaging. 01(02), 39-42.

Widians, J. A., Pakpahan, H. S., Budiman, E., Haviluddin, \& Soleha, M. (2019). Klasifikasi Jenis Bawang Menggunakan Metode KNearest Neighbor Berdasarkan Ekstraksi Fitur Bentuk dan Tekstur. Jurti, 3(2), 139-146. 